\title{
Evaluating the impact of COVID-19 on male reproduction
}

\author{
Yu Tian and Li-quan Zhou \\ Institute of Reproductive Health, Center for Reproductive Medicine, Tongji Medical College, Huazhong University \\ of Science and Technology, Wuhan, Hubei, China
}

Correspondence should be addressed to L Zhou; Email: zhouliquan@hust.edu.cn

\begin{abstract}
Invasion or damage of the male reproductive system is one of the reported outcomes of viral infection. Current studies have documented that SARS-CoV-2, which causes COVID-19, can damage the male reproductive system in large part by inflammatory damage caused by a cytokine storm. However, whether SARS-CoV-2 can infect the human testis directly and enter semen is controversial. Other adverse effects of SARS-CoV-2 on male reproduction are also of concern and require comprehensive evaluation. Here, we analyze the invasiveness of SARS-CoV-2 in the testis and examine reported mechanisms by which SARS-CoV-2 interferes with male reproduction. Long-term implications of SARS-CoV-2 infection on male reproduction are also discussed. It should be emphasized that although COVID-19 may induce testicular damage, a substantial decrease in male reproductive capacity awaits clinical evidence. We propose that there is an urgent need to track male COVID-19 patients during their recovery. The development of suitable experimental models, including human reproductive organoids, will be valuable to further investigate the viral impact on reproduction for current and future pandemics.

Reproduction (2021) 161 R37-R44
\end{abstract}

\section{Introduction}

In the past months of combating COVID-19 (coronavirus disease 19), over 50 million people have been infected by the severe acute respiratory syndrome coronavirus 2 (SARS-CoV-2), and the impact of the disease may continue for several years. Moreover, the actual number of infected individuals worldwide has been estimated to be 12 times higher than official numbers as of July 2020 (Rahmandad et al. 2020). Although primarily a respiratory disease, this huge base amplifies the adverse effects of less severe aspects of COVID-19 and invites further evaluation. SARS-CoV-2 shares $\sim 80 \%$ amino acid sequence with severe acute respiratory syndrome coronavirus 1 (SARS-CoV-1) (Gralinski \& Menachery 2020) that caused more than 8000 infections in 2003. Both viruses use transmembrane serine protease 2 (TMPRSS2) and the receptor angiotensin-converting enzyme 2 (ACE2) to infect host cells. Besides lung, ACE2 is expressed in many tissues including the cardiovascular system, gastrointestinal tract and liver. Correspondingly, damage to those organs was observed in the COVID-19 patients (Xiao et al. 2020, Zhang et al. 2020b, Zheng et al. 2020). Notably, testis also was reported to express ACE2 in different cell types (Wang \& Xu 2020) and it is worth noting that being male is a contributing factor in COVID19 deaths (Williamson et al. 2020). In related studies, male patients showed higher plasma levels of innate immune cytokines than female patients (Takahashi et al. 2020) and a high proportion of male patients were of reproductive age (Guan et al. 2020). Therefore, whether SARS-CoV-2 infection impairs the male reproductive system becomes an issue that deserves further investigation.

Current studies confirm that SARS-CoV-2 can affect the male reproductive system. Abnormal levels of sex hormones and declining sperm quality were observed in patients during and after recovery from COVID-19. Moreover, severe inflammation damage was detected in testes and the presence of virus in testicular tissue was reported at autopsy. Detrimental effects on male fertility have been reported during infections with Zika (ZIKV), mumps (MuV), and SARS-CoV-1 viruses, but the picture is less complete for COVID-19. A better understanding of the mechanisms of infection and pathophysiology will require long-term surveillance and investigation. However, previous studies of the aforementioned viruses, especially SARS-CoV-1, can supply meaningful guidance for analyzing the effect of COVID-19 on male reproduction. Here, based on the available evidence, we discuss tropism of SARS-CoV-2 for testicular cells, and analyze known and potential mechanisms by which SARS-CoV-2 affects male reproductive health with the aim of providing a reference for further investigations and treatment of COVID-19.

\section{The molecular basis of SARS-CoV-2 infecting the male reproductive system}

The testis consists of seminiferous tubules and interstitial cells that are separated by a basal lamina and are 
important for spermatogenesis and hormone regulation, respectively. Within seminiferous tubules, germ cells mature centripetally between adjacent Sertoli cells. Meiotic and maturing spermatocytes are separated from more peripheral spermatogonia and pre-leptotene spermatocytes by cell-cell junctions between Sertoli cells that constitute a blood-testis barrier (BTB). This provides an immune-privileged microenvironment for maturing sperm by limiting the exchange of substances between interstitium and germ cells. Fully grown spermatids are released into the lumen of seminiferous tubules which drain into the rete testis and spermatozoa pass into the epididymis for maturation and storage (Suede et al. 2020). The interstitium of the testis is mainly composed of Leydig cells (LC), as well as smaller populations of immune, myoid and fibroblast cells. Testosterone secreted by LCs plays a crucial role in spermatogenesis and in maintaining secondary sex characteristics (Heinrich \& DeFalco 2020). Overall, there is a highly integrated synergism among all testicular cells in ensuring male fertility and adverse effects on the testis risk male reproductive health (Fig. 1).

Previous bioinformatic analyses have documented the cellular distribution of the ACE2 receptor in testes
(Liu et al. 2020, Shen et al. 2020, Wang \& Xu 2020). SARS-CoV-2 and SARS-CoV-1 share the common spike (S) protein. Endocytosis of SARS-CoV-2 virus into target cells depends on the recognition of the ACE2 receptor by the viral S protein (Hoffmann et al. 2020) and SARS-CoV-2 has a higher affinity for the receptor than SARS-CoV-1 (Wrapp et al. 2020). Within the testis, ACE2 is expressed mainly in SC, LC, and spermatogonia cells (Wang \& Xu 2020). Expression of ACE2 in testes varies with age and men in their 30s had the highest expression of ACE2 (Liu et al. 2020, Shen et al. 2020). Thus, the testis is a potential target of SARS-CoV-2 and could adversely affect male fertility. Moreover, once the virus is present in semen, sperm that express ACE2 may also be infected by SARS-CoV-2. Theoretically, sperm could become vectors in the spread of COVID-19 which recently has been reviewed (Aitken 2020).

However, a viral infection of cells requires cofactors, particularly the TMPRSS2 protein which plays a vital role in enhancing SARS-CoV-2 entry by priming the $\mathrm{S}$ protein (Li et al. 2003, Matsuyama et al. 2010). Although spermatogonia and spermatozoon express TMPRSS2, high co-expression of the two proteins is not observed

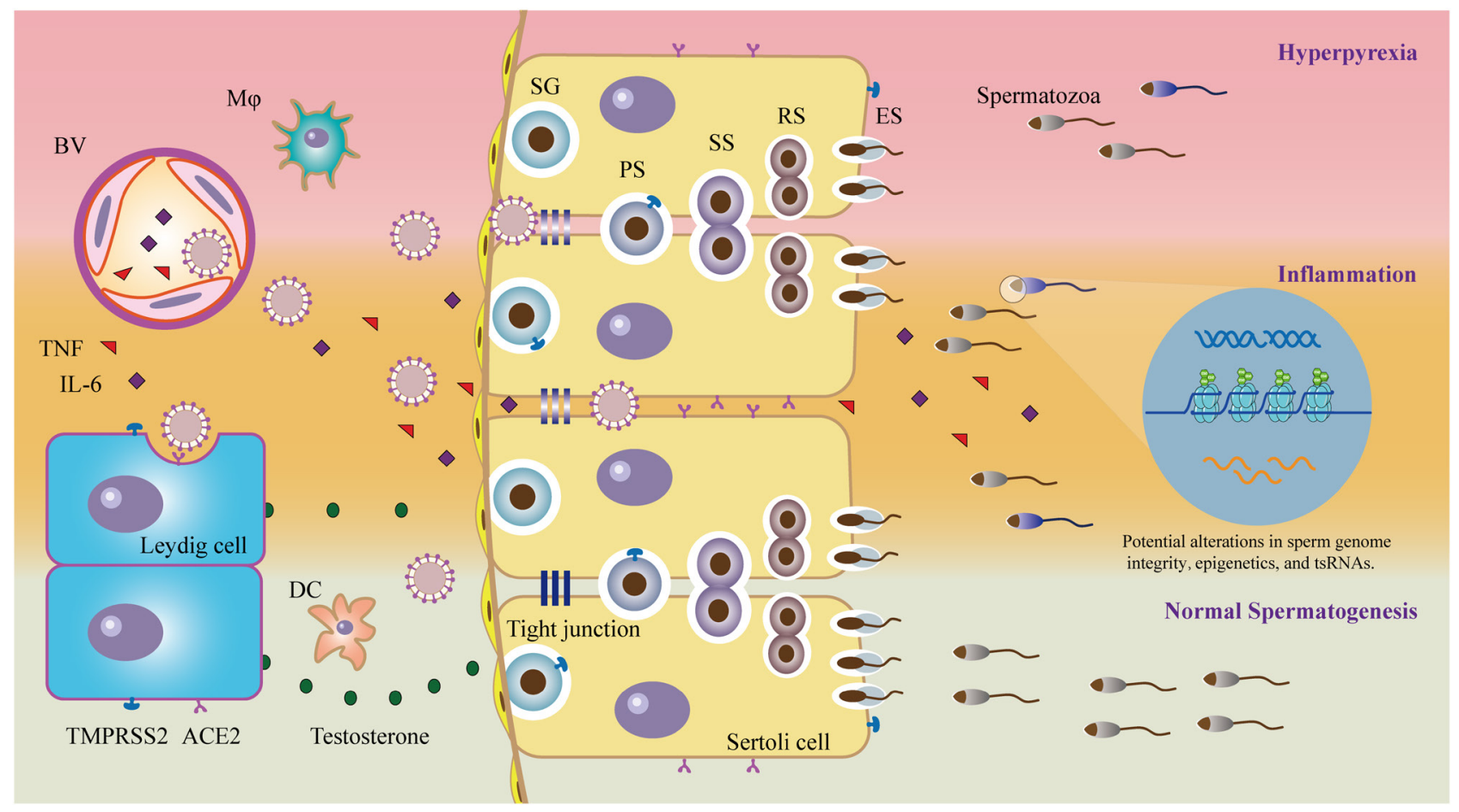

Figure 1 Potential routes of SARS-CoV-2 affecting male reproductive system. SARS-CoV-2 and high levels of cytokines may enter testicular tissue via hematogenous dissemination. LCs could be attacked by cytokines (or SARS-CoV-2 virus) which would influence testosterone secretion and spermatogenesis. Additionally, the BTB which normally prevents viral invasion is susceptible to the cytokine-mediated inflammation. The severe cytokine storm associated with SARS-CoV-2 infection could cause orchitis and epididymitis. Additional factors, including hyperpyrexia, inflammatory destruction of the BTB may increase the probability of virus crossing the BTB. Considering low co-expression of ACE2 and TMPRSS2 in SCs and germ cells, further investigations will be needed to determine the possibility of sexual transmission. Sperm DNA fragmentation, alterations in epigenome and sperm tsRNAs may be mediated indirectly by fever, inflammation, and psychological factors. Studies to investigate possible adverse effect on future pregnancies and progeny are also warranted. BV, blood vessel; M $\varphi$, macrophage; DC, dendritic cell; SG, spermatogonia; PS, primary spermatocyte; SS, secondary spermatocyte; RS, round spermatid; ES, elongating spermatid. 
in testicular cells (Pan et al. 2020, Stanley et al. 2020). For example, spermatogonia possess high levels of TMPRSS2, but low levels of ACE2 and SCs express high levels of ACE2, but low levels of TMPRSS2 (Liu et al. 2020, Pan et al. 2020, Wang \& Xu 2020). Other cofactors, including endosomal cysteine proteases cathepsin L and cathepsin B facilitate SARS-CoV-1 entry, but are primarily expressed in spermatocytes and testicular macrophages, respectively (Liu et al. 2020).

Other potential cell receptors of the $S$ protein include CD147, CD26, and Neuropilin-1 were reported recently, but need further validation. CD147 is mainly expressed in spermatocytes, but other testicular cells including SCs have a moderate expression (Liu et al. 2020, Wang et al. 2020). CD26 acts as a receptor of the middle east respiratory syndrome (MERS) coronavirus and its interaction with S protein has been documented (Vankadari \& Wilce 2020). Meanwhile, the infection efficiency of SARS-CoV-2 mediated by Neuropilin- 1 and TMPRSS2 reached half that mediated by ACE2 and TMPRSS2 (Cantuti-Castelvetri et al. 2020). Distribution of CD26 and neuropilin-1 in testis requires documentation, the role of these potential receptors warrant additional study. Overall, the expression of ACE2 and other potential receptors in the testes suggests a possible tropism of SARS-CoV-2 to the testis. However, based on current evidence it is not possible to conclude that SARS-CoV-2 infects testicular cells directly by interacting with ACE2 or other receptors. Moreover, given the low level of Co-expression of ACE2 and other cofactors in testes, the probability of SARS-CoV-2 infecting cells of the testis via ACE2 remains low.

\section{Possible mechanisms of SARS-CoV-2 affecting male reproduction}

The main mechanisms of viruses impacting male reproduction can be summarized as follows: (a) direct viral invasion of germ cells and spreading the viruses via sexual transmission; (b) virus affecting reproductive endocrinology necessary to maintain secondary sexual characteristics; (c) a secondary viral infection-induced inflammation response that severely affects the testes; and (d) viral infection-triggered fevers that interfere with the normal reproductive physiology. Of note, the above mechanisms often coexist and have a synergistic effect on mediating the impairment. Besides, the male reproductive system may also be impacted by drugs used to treat a viral infection, with the major reason to be gonadotoxic effect of drugs, such as glucocorticoids and interferons (Drobnis \& Nangia 2017, Li et al. 2020c). Intriguingly, the binding of SARS-CoV-2 to ACE2 could cause up-regulation of angiotensin II, which may induce adverse effects on male fertility (Welter et al. 2014, Aitken 2020). Based on the current studies on SARS-CoV-2 and evidence that other viruses disrupted male reproduction, we analyzed known and potential mechanisms that SARS-CoV-2 affected male reproduction.

\section{Can SARS-CoV-2 directly infect the testis?}

Evidence for SARS-CoV-2 infection of the testis is not compelling. In 2003-2004, several groups reported histopathological examination of testes from SARSCoV-1 deaths. More reported negative (Zhang et al. 2003, Zhao et al. 2003b, Ding et al. 2004) than positive (Zhao et al. 2003a,c) results in evaluating the presence of the virus. Similarly, SARS-CoV-2 virus was not present in testis samples from a COVID-19 patient who died in the acute phase (Song et al. 2020). However, another study reported that the virus could be detected in multiple organs including testis, with varying degrees of germ cell reduction and damage (Bian et al. 2020). Recently, Yang et al. tested testis samples from 12 deceased COVID-19 patients. The virus was detected in only one patient who had a high viral load. The SARSCoV-2 virus was not present in seminiferous tubules, but only in the interstitium, and it was unclear whether the virus came from blood rather than infection of the testis (Yang et al. 2020b).

However, whether the virus can be present in the testis does not entirely depend on the viral infection. There are other conditions where the virus might enter and disrupt testicular tissue, including high blood viral load, local inflammation, hyperpyrexia and imperfect BTB. Thus, the possibility of SARS-CoV-2 directly disrupting testis cannot be ruled out, but in the mild COVID-19 patients without risk factors, it seems unlikely.

\section{The possibility of sexual transmission of SARS-CoV-2}

Current evidence does not support sexual transmission of the SARS-CoV-2 virus. Six small cohort studies (Guo et al. 2020, Holtmann et al. 2020, Li et al. 2020b, Ma et al. 2020, Pan et al. 2020, Song et al. 2020) from three counties and one case report (Paoli et al. 2020a) from Italy did not detect viral nucleic acids in semen samples from mildly affected and recover-stage male patients. Two independent studies also reported no SARS-CoV-2 virus in prostate fluid (Quan et al. 2020, Zhang et al. 2020a). However, one study showed that SARS-CoV-2 could be shed into semen. In this study, among the 23 clinical recovered and 15 acute phase patients, 2 (8.7\%) and $4(26.7 \%)$ patients, respectively, tested positive for virus components in their semen (Li et al. 2020a) which stands in sharp contrast to previous studies. But the detailed methodology of false-positives caused by sampling and detection errors was not provided (Paoli et al. 2020b). All these studies suffer from small sample sizes and the demographics of patients in convalescence after mild infection may have introduced selection bias. In addition, the abundance of viral RNA in semen was low compared to other tissues and procedures for the collection of ejaculates is vulnerable to contamination. Larger and multicenter trials are needed to conclude compelling results as to the presence or absence of 
SARS-CoV-2 in semen, especially for patients early in the disease course or asymptomatic. However, according to available studies, the probability of virus entry into semen in mild or recover-stage patients is very low. Collectively, the absence of SARS-CoV-2 in the semen moots the possibility of sexual transmission of COVID-19.

\section{Orchitis mediated by SARS-CoV-2-induced severe inflammation}

The BTB confers an isolated immune-privileged microenvironment for sperm in the testis. However, serious inflammation induced by infection can disrupt the BTB resulting in orchitis which adversely affects testicular function and male fertility. Notably, SARSCoV-1 can cause severe orchitis with broadly damaged germ cells, few mature spermatozoa, thickened basement membranes and leukocyte infiltration. The absence of SARS-CoV-1 in the testis indicates that inflammation rather than the direct viral infection caused the histopathology and that substantial orchitis can occur in SARS patients (Xu et al. 2006).

Similar histopathological changes have been reported in COVID-19 patients. Testicular samples from 2 of 10 autopsies had orchitis of unknown origin, although few details were provided (Nunes Duarte-Neto et al. 2020). In two separate reports, histopathological changes consistent with orchitis were observed in 6 and 11 of 12 deceased COVID-19 patients (Li et al. $2020 b$, Yang et al. 2020b). These included inflammatory damages of seminiferous tubules with interstitial edema, congestion, inflammatory cell infiltrate and red blood cell exudation. Thinning of seminiferous tubules and desquamation of intratubular cells were also observed. There were decreased numbers of LCs in the interstitium. SCs were characterized by swelling, vacuolation and cytoplasmic rarefaction accompanied by marked shedding of cells from the basement membrane. In addition, eight patients had varying degrees of impaired spermatogenesis with hypospermatogenesis, maturation arrest and mild peritubular hyalinization (Yang et al. 2020b). Li et al. also detected the semen samples from COVID-19 inpatients, which showed that the sperm concentration declined with elevated levels of interleukin-6 (IL-6), tumor necrosis factor- $\alpha$ (TNF$\alpha)$, and monocyte chemoattractant protein-1(MCP-1) in the semen compared with controls (Li et al. 2020b). Most importantly, in both studies, no SARS-CoV-2 virus was detected in those testis samples in which orchitis was confirmed, suggesting that inflammatory response rather than viral infection dominated these pathological changes.

Therefore, we speculate that a cytokine storm induced by SARS-CoV-2 plays a critical role in the observed orchitis. Patients with severe COVID-19 infection have high levels of plasma cytokines including IL-2, IL-6, IL-7, IL-10, TNF- $\alpha$, and MCP-1 (Chen et al. 2020, Huang et al. 2020). Male patients have a weaker T cell response and higher plasma level of innate immune cytokines than female patients, which is associated with the poor disease outcome (Takahashi et al. 2020). Unlike viral infections, cytokines such as IL- 6 and TNF- $\alpha$ aggressively disrupt the integrity of the BTB (Li et al. 2006, Zhang et al. 2014). When hypercytokinaemia happens, it is likely that cytokines pass through the BTB and induce inflammation in seminiferous tubules. This is consistent with previous studies that implicated IL-6 disruption of the BTB in the pathogenesis of autoimmune orchitis (Rival et al. 2006, Perez et al. 2012). In adult infection with MuV (virus causing mumps), TNF- $\alpha$ can disrupt the BTB to cause orchitis and male infertility (Wu et al. 2019). Orchitis not only disrupts the immune balance of the testis microenvironment, but also impairs the seminiferous epithelium and spermatogonial stem cells. These detrimental effects are substantial and make complete recovery unlikely. Additionally, inflammation increases the probability of the virus entering the testis and it is not surprising that SARS-CoV-2 is detected in testes of patients with severe disease (Bian et al. 2020).

\section{SARS-CoV-2 and dysfunction of hypothalamus- pituitary-gonad axis}

Androgens secreted from the testis are essential to maintain secondary male sex characteristics. Unlike spermatogenesis that occurs solely within the testis, the synthesis of male sex hormones involves a hypothalamus, pituitary, gonad (HPG) axis. Previous reports reported that male patients infected with SARS-CoV-1 had elevated luteinizing hormone (LH), follicle-stimulating hormone (FSH), prolactin (PRL) and decreased estradiol $(\mathrm{E})$, progesterone $(\mathrm{P})$, and testosterone $(\mathrm{T})$ plasma levels (Wang et al. 2005, Wei et al. 2010). COVID-19 patients recapitulate these abnormalities. In a cohort study of 45 male COVID-19 patients, $68.6 \%$ and $48.6 \%$ of patients had low $\mathrm{T}$ and dihydrotestosterone levels, respectively (Schroeder et al. 2020). In comparison to patients in remission, 31 males in critical care (or deceased) had higher $\mathrm{LH}$, lower total $\mathrm{T}$ and calculated free $\mathrm{T}$ which suggests hypogonadism in severely ill patients (Rastrelli et al. 2020). These and an additional study (Salciccia et al. 2020) indicate an inverse correlation between $\mathrm{T}$ levels and inflammatory factors. A retrospective single-center study involving 119 patients reported that male patients had no differences in serum levels of T compared with controls but had elevated LH levels and significantly decreased ratios of T/LH. There also was a negative correlation between $\mathrm{T} / \mathrm{LH}$ ratios and inflammatory markers (Ma et al. 2020). Taken together, these findings suggest an impact of SARS-CoV-2 infection on the HPG axis and highlight the role of inflammation.

Impaired Leydig cells reduce androgen hormone secretion which feedbacks on the pituitary and could 
account for decreased T and increased LH. However, previous studies indicated SARS-CoV-1 RNA was detected in the acidophilic cells of the pituitary and function of adenohypophyseal endocrine cells in infected patients was adversely affected (Zhang et al. 2003, Wei et al. 2010). Possible effects of COVID-19 on hypothalamus and pituitary have also been proposed (Ur \& Verma 2020), although inadequately documented. Most importantly, the dysfunction of hypothalamus and pituitary not only affect the sex hormones but other hormones and adrenaline that help maintain normal sexual functions (Bhasin et al. 2007).

Therefore, abnormal sex hormone levels may be attributable to multiple targets in the HPG axis. Intriguingly, whether this result is caused by a virus affecting the pituitary or the testis, inflammation seems to play a vital role in it. Of course, other factors including corticosteroid treatment and mental stresses may be considerable contributors. Additionally, the long-term implications of altered sex hormones on male fertility needs to be recognized. There is a precedence in that the ZIKV induced testicular atrophy by decreasing testosterone (Uraki et al. 2017). More attention needs to paid to the risk of SARS-CoV-2 on the HPG axis, and larger studies will be required to evaluate hypogonadism and sexual dysfunction caused by abnormal sex hormone levels in men with COVID-19.

\section{Febrility caused by SARS-CoV-2 may disrupt spermatogenesis}

Decreased sperm number or increased sperm DNA fragmentation has been reported in males recovering from COVID-19 (Ma et al. 2020). Four patients with moderate infection and fever had impaired sperm quality (Holtmann et al. 2020), but whether this was due to inflammation or fever remained unresolved. Fever associated with infections has a temporary adverse impact on spermatogenesis and sperm quality, but usually does not result in irreversible damage to male fertility. The adverse effect on sperm is characterized by decreased concentrations, alterations in morphology, diminished motility and increased DNA fragmentation (MacLeod 1951, Evenson et al. 2000). These defects can persist for months after the end of fever (Carlsen et al. 2003, Sergerie et al. 2007).

In patients infected with SARS-CoV-2, fever is one of the most common symptoms (Huang et al. 2020), but is often overshadowed by other manifestations of the disease. Increased sperm DNA fragmentation results in decreased fertility, poor embryo quality, and increased embryonic loss (Simon et al. 2011, Robinson et al. 2012). Of note, impaired sperm quality may persist and males recovering from COVID-19 should be monitored for gamete quality and delayed procreation may be required.

\section{Possible impact on reproduction of patients recovering from COVID-19}

The effects of SARS-CoV-2 infection on male reproduction are generally consistent with previous results on SARS-CoV-1 (Table 1). Sexual transmission for patients recovering from COVID-19 seems unlikely, but the risk of impaired spermatogenesis has been observed in patients with moderate infection and in convalescents (Holtmann et al. 2020, Ma et al. 2020). The duration and severity of these abnormalities and their potential impact on progeny are not known. Thus, it will be important to carry out prospective and long-term studies for further clarification of adverse consequences of COVID-19. Establishing sperm quality as well as seeking clinical

Table 1 Summary of known adverse effects of SARS-CoV and SARS-CoV-2 on male reproduction.

\begin{tabular}{|c|c|c|c|c|}
\hline \multirow[b]{2}{*}{ Adverse effects } & \multirow[b]{2}{*}{ SARS-CoV-1 } & \multirow[b]{2}{*}{ SARS-CoV-2 } & \multicolumn{2}{|r|}{ References } \\
\hline & & & SARS-CoV-1 & SARS-CoV-2 \\
\hline \multirow[t]{2}{*}{$\begin{array}{l}\text { Virus was detected } \\
\text { in testicular tissues }\end{array}$} & + & + & $\begin{array}{l}\text { Zhao et al. (2003c), } \\
\text { Zhao et al. (2003a) }\end{array}$ & Bian et al. (2020), Yang et al. (2020b) \\
\hline & - & - & $\begin{array}{l}\text { Zhang et al. (2003), } \\
\text { Zhao et al. (2003b), } \\
\text { Ding et al. (2004) }\end{array}$ & Song et al. (2020) \\
\hline \multirow{2}{*}{$\begin{array}{l}\text { Virus was detected } \\
\text { in semen }\end{array}$} & ND & + & & Li et al. (2020a) \\
\hline & & - & & $\begin{array}{l}\text { Guo et al. (2020), Holtmann et al. (2020), } \\
\text { Li et al. (2020b), Ma et al. (2020), Pan } \\
\text { et al. (2020), Song et al. (2020) }\end{array}$ \\
\hline $\begin{array}{l}\text { Semen parameters } \\
\text { abnormalities }\end{array}$ & ND & + & & Holtmann et al. (2020), Ma et al. (2020) \\
\hline Orchitis & + & + & Xu et al. (2006) & $\begin{array}{l}\text { Li et al. (2020b), Nunes Duarte-Neto } \\
\text { et al. (2020), Yang et al. (2020b) }\end{array}$ \\
\hline $\begin{array}{l}\text { Sex hormone } \\
\text { abnormalities }\end{array}$ & + & + & $\begin{array}{l}\text { Wang et al. (2005), } \\
\text { Wei et al. (2010) }\end{array}$ & $\begin{array}{l}\text { Ma et al. (2020), Rastrelli et al. (2020), } \\
\text { Salciccia et al. (2020), Schroeder } \\
\text { et al. (2020) }\end{array}$ \\
\hline Potential long-term effects & ND & ND & & \\
\hline
\end{tabular}

+ , indicates studies were performed and results were positive; -, indicates studies were performed and results were negative; ND, not determined indicates that assays were not performed. 
examination and consultation are recommended before a planned pregnancy for convalescent patients.

Besides parameters that can be quantified, there may be some subtle alterations in spermatozoa. Environmental effects, including lifestyle, can be translated into heritable information stored in the epigenome and RNA of gametes that impact progeny (Zhang et al. 2019). For example, obesity is a phenotype that has a high probability of inheritance from overweight fathers. In a region associated with appetite control, a dramatic reprogramming of sperm DNA methylation is observed after bariatric surgeryinduced weight loss (Donkin et al. 2016). Moreover, in mouse models of metabolic disorders, if male mice are given a high-fat diet (HFD), the expression profiles and modifications of the sperm tRNA-derived small RNAs (tsRNAs) is altered. Normal zygotes injected with tsRNAs from HFD mice also developed the metabolic disorder phenotype (Chen et al. 2016). These intriguing lines of evidence suggest that environmental inputs can have a profound effect on offspring. Given that the period of infection with SARS-CoV-2 is short and spermatogonial self-renewal, the possibility of a transgenerational effect may be low. Nevertheless, whether COVID-19-mediated adverse effects can act on sperm and induce abnormal infants will require long-term surveillance.

\section{Development of experimental models for future investigation}

Considering the long-term threat to international public health posed by COVID-19, the effect of SARS-CoV-2 infection on male reproduction needs systematic investigation. However, human tissue from autopsies studies is difficult to obtain and often inadequate for investigations of molecular mechanisms. The establishment of human ACE2 transgenic mice (Bao et al. 2020) and Rhesus macaques (Shan et al. 2020) provide models but fail to mimic human reproduction physiology. Human organoids have played a role in studying susceptibility of liver and pancreas to SARSCoV-2 (Yang et al. 2020a, Zhao et al. 2020), but the development of complete testis organoids is still in its infancy (Oliver \& Stukenborg 2020). A simplified human testicular organoid to mimic the ZIKA virus infection has been reported, but lacks the integral structure of the BTB (Strange et al. 2018). Thus, further improvement of experimental models of the human reproductive system is vital to develop strategies to cope with the threat of current and future testis-tropic viruses.

\section{Conclusions and perspectives}

The impact of SARS-CoV-2 on male reproduction has been confirmed in preliminary studies and summarized in Fig. 1. A virus-induced cytokine storm appears to be the major and most destructive effect of COVID-19 on male testes. Because of the low levels of ACE2 and TMPRSS2 expressed in the testis, the probability of SARSCoV-2 infection in an ACE2-dependent manner remains relatively low. Instead, severe inflammation secondary to viral infection could disrupt the BTB and cause orchitis. The subsequent damage of germ cells and interstitium would adversely impact spermatogenesis and hormone production within the testes. Breaching the protective BTB could account for the seeding of the SARS-CoV-2 virus in the testis. If so, the adventitious presence of the virus in testes or seminal fluid should be low and it seems unlikely that SARS-CoV-2 is sexually transmitted.

While anti-inflammatory therapies will be helpful to treat acute orchitis, fertility evaluation and prepregnancy consultation are important for convalescent patients. Long-term follow-up studies should help validate the preliminary studies and provide guidance for the need for assisted reproductive technologies. Development of improved experimental models of human male reproduction will be valuable to determine the pathophysiology of SARS-CoV-2 viral infections. It will also be important to evaluate and monitor possible long-term transgenerational effects.

\section{Declaration of interest}

The authors declare that there is no conflict of interest that could be perceived as prejudicing the impartiality of this review.

\section{Funding}

This work was supported by National Key R\&D Program of China (2018YFC1004502, 2018YFC1004001) and the National Natural Science Foundation of China (NSFC 31771661).

\section{Author contribution statement}

Li-quan Zhou conceived the ideas and Yu Tian wrote the manuscript.

\section{References}

Aitken RJ 2020 COVID-19 and human spermatozoa - potential risks for infertility and sexual transmission. Andrology In press. (https://doi. org/10.1111/andr.12859)

Bao L, Deng W, Huang B, Gao H, Liu J, Ren L, Wei Q, Yu P, Xu Y, Qi F et al. 2020 The pathogenicity of SARS-CoV-2 in hACE2 transgenic mice. Nature 583 830-833. (https://doi.org/10.1038/s41586-020-2312-y)

Bhasin S, Enzlin P, Coviello A \& Basson R 2007 Sexual dysfunction in men and women with endocrine disorders. Lancet 369 597-611. (https://doi. org/10.1016/S0140-6736(07)60280-3)

Bian X-W, Yao X-H, Ping Y-F, Yu S, Shi Y, Luo T, He Z-C, Tang R, Chen C, Fu W-J et al. 2020 Autopsy of COVID-19 victims in China. National Science Review 7 1414-1418. (https://doi.org/10.1093/nsr/nwaa123)

Cantuti-Castelvetri L, Ojha R, Pedro LD, Djannatian M, Franz J, Kuivanen S, Kallio K, Kaya T, Anastasina M, Smura T et al. 2020 Neuropilin-1 facilitates SARS-CoV-2 cell entry and provides a possible pathway into the central nervous system. bioRxiv 2020.06.07.137802.

Carlsen E, Andersson AM, Petersen JH \& Skakkebaek NE 2003 History of febrile illness and variation in semen quality. Human Reproduction 18 2089-2092. (https://doi.org/10.1093/humrep/deg412) 
Chen Q, Yan M, Cao Z, Li X, Zhang Y, Shi J, Feng GH, Peng H, Zhang X, Zhang $\mathbf{Y}$ et al. 2016 Sperm tsRNAs contribute to intergenerational inheritance of an acquired metabolic disorder. Science 351 397-400. (https://doi.org/10.1126/science.aad7977)

Chen N, Zhou M, Dong X, Qu J, Gong F, Han Y, Qiu Y, Wang J, Liu Y, Wei Y et al. 2020 Epidemiological and clinical characteristics of 99 cases of 2019 novel coronavirus pneumonia in Wuhan, China: a descriptive study. Lancet 395 507-513. (https://doi.org/10.1016/S01406736(20)30211-7)

Ding Y, He L, Zhang Q, Huang Z, Che X, Hou J, Wang H, Shen H, Qiu L, Li Z et al. 2004 Organ distribution of severe acute respiratory syndrome (SARS) associated coronavirus (SARS-CoV) in SARS patients: implications for pathogenesis and virus transmission pathways. Journal of Pathology 203 622-630. (https://doi.org/10.1002/path.1560)

Donkin I, Versteyhe S, Ingerslev LR, Qian K, Mechta M, Nordkap L, Mortensen B, Appel EV, Jorgensen N, Kristiansen VB et al. 2016 Obesity and bariatric surgery drive epigenetic variation of spermatozoa in humans. Cell Metabolism 23 369-378. (https://doi.org/10.1016/j. cmet.2015.11.004)

Drobnis EZ \& Nangia AK 2017 Immunosuppressants and male reproduction. Advances in Experimental Medicine and Biology 1034 179-210. (https://doi.org/10.1007/978-3-319-69535-8_12)

Duarte-Neto AN, De Almeida Monteiro RA, Da Silva LFF, Malheiros D, De Oliveira EP, Theodoro Filho J, Pinho JRR, Soares Gomes-Gouvea M, Salles APM, De Oliveira IRS et al. 2020 Pulmonary and systemic involvement of COVID-19 assessed by ultrasound-guided minimally invasive autopsy. Histopathology 77 186-197. (https://doi.org/10.1111/ his.14160)

Evenson DP, Jost LK, Corzett M \& Balhorn R 2000 Characteristics of human sperm chromatin structure following an episode of influenza and high fever: a case study. Journal of Andrology 21 739-746.

Gralinski LE \& Menachery VD 2020 Return of the coronavirus: 2019-nCoV. Viruses 12 135. (https://doi.org/10.3390/v12020135)

Guan WJ, Ni ZY, Hu Y, Liang WH, Ou CQ, He JX, Liu L, Shan H, Lei CL, Hui DSC et al. 2020 Clinical characteristics of coronavirus disease 2019 in China. New England Journal of Medicine 382 1708-1720. (https://doi. org/10.1056/NEJMoa2002032)

Guo L, Zhao S, Li W, Wang Y, Li L, Jiang S, Ren W, Yuan Q, Zhang F, Kong F et al. 2020 Absence of SARS-CoV-2 in semen of a COVID-19 patient cohort. Andrology In press. (https://doi.org/10.1111/andr.12848)

Heinrich A \& DeFalco T 2020 Essential roles of interstitial cells in testicular development and function. Andrology 8 903-914. (https://doi. org/10.1111/andr.12703)

Hoffmann $M$, Kleine-Weber $H$, Schroeder S, Kruger $N$, Herrler $T$, Erichsen S, Schiergens TS, Herrler G, Wu NH, Nitsche A et al. 2020 SARS-CoV-2 cell entry depends on ACE2 and TMPRSS2 and is blocked by a clinically proven protease inhibitor. Cell 181 271.e8-280.e8. (https://doi.org/10.1016/j.cell.2020.02.052)

Holtmann N, Edimiris P, Andree M, Doehmen C, Baston-Buest D, Adams O, Kruessel JS \& Bielfeld AP 2020 Assessment of SARS-CoV-2 in human semen-a cohort study. Fertility and Sterility 114 233-238, 30519-30517. (https://doi.org/10.1016/j.fertnstert.2020.05.028)

Huang C, Wang Y, Li X, Ren L, Zhao J, Hu Y, Zhang L, Fan G, Xu J, Gu X et al. 2020 Clinical features of patients infected with 2019 novel coronavirus in Wuhan, China. Lancet 395 497-506. (https://doi.org/10.1016/S01406736(20)30183-5)

Li W, Moore MJ, Vasilieva N, Sui J, Wong SK, Berne MA, Somasundaran M, Sullivan JL, Luzuriaga K, Greenough TC et al. 2003 Angiotensinconverting enzyme 2 is a functional receptor for the SARS coronavirus. Nature 426 450-454. (https://doi.org/10.1038/nature02145)

Li MW, Xia W, Mruk DD, Wang CQ, Yan HH, Siu MK, Lui WY, Lee WM \& Cheng CY 2006 Tumor necrosis factor \{alpha\} reversibly disrupts the blood-testis barrier and impairs Sertoli-germ cell adhesion in the seminiferous epithelium of adult rat testes. Journal of Endocrinology 190 313-329. (https://doi.org/10.1677/joe.1.06781)

Li D, Jin M, Bao P, Zhao W \& Zhang S 2020a Clinical characteristics and results of semen tests among men with coronavirus disease 2019. JAMA Network Open 3 e208292. (https://doi.org/10.1001/ jamanetworkopen.2020.8292)

Li H, Xiao X, Zhang J, Zafar MI, Wu C, Long Y, Lu W, Pan F, Meng T, Zhao K et al. 2020b Impaired spermatogenesis in COVID-19 patients. EClinicalmedicine 28 100604. (https://doi.org/10.1016/j. eclinm.2020.100604)
Li R, Yin T, Fang F, Li Q, Chen J, Wang Y, Hao Y, Wu G, Duan P, Wang Y et al. 2020c Potential risks of SARS-CoV-2 infection on reproductive health. Reproductive Biomedicine Online 41 89-95. (https://doi. org/10.1016/j.rbmo.2020.04.018)

Liu X, Chen Y, Tang W, Zhang L, Chen W, Yan Z, Yuan P, Yang M, Kong S, Yan L et al. 2020 Single-cell transcriptome analysis of the novel coronavirus (SARS-CoV-2) associated gene ACE2 expression in normal and non-obstructive azoospermia (NOA) human male testes. Science China: Life Sciences 63 1006-1015. (https://doi.org/10.1007/s11427020-1705-0)

Ma L, Xie W, Li D, Shi L, Ye G, Mao Y, Xiong Y, Sun H, Zheng F, Chen Z et al. 2020 Evaluation of sex-related hormones and semen characteristics in reproductive-aged male COVID-19 patients. Journal of Medical Virology In Press. (https://doi.org/10.1002/jmv.26259)

MacLeod J 1951 Effect of chickenpox and of pneumonia on semen quality. Fertility and Sterility 2 523-533. (https://doi.org/10.1016/s00150282(16)30726-9)

Matsuyama S, Nagata N, Shirato K, Kawase M, Takeda M \& Taguchi F 2010 Efficient activation of the severe acute respiratory syndrome coronavirus spike protein by the transmembrane protease TMPRSS2. Journal of Virology 84 12658-12664. (https://doi.org/10.1128/JVI.01542-10)

Oliver E \& Stukenborg JB 2020 Rebuilding the human testis in vitro. Andrology 8 825-834. (https://doi.org/10.1111/andr.12710)

Pan F, Xiao X, Guo J, Song Y, Li H, Patel DP, Spivak AM, Alukal JP, Zhang X, Xiong C et al. 2020 No evidence of severe acute respiratory syndromecoronavirus 2 in semen of males recovering from coronavirus disease 2019. Fertility and Sterility 113 1135-1139. (https://doi.org/10.1016/j. fertnstert.2020.04.024)

Paoli D, Pallotti F, Colangelo S, Basilico F, Mazzuti L, Turriziani O, Antonelli G, Lenzi A \& Lombardo F 2020a Study of SARS-CoV-2 in semen and urine samples of a volunteer with positive naso-pharyngeal swab. Journal of Endocrinological Investigation 43 1819-1822. (https:// doi.org/10.1007/s40618-020-01261-1)

Paoli D, Pallotti F, Turriziani O, Mazzuti L, Antonelli G, Lenzi A \& Lombardo F 2020b SARS-CoV-2 presence in seminal fluid: myth or reality. Andrology In press. (https://doi.org/10.1111/andr.12825)

Perez CV, Sobarzo CM, Jacobo PV, Pellizzari EH, Cigorraga SB, Denduchis B \& Lustig L 2012 Loss of occludin expression and impairment of bloodtestis barrier permeability in rats with autoimmune orchitis: effect of interleukin 6 on Sertoli cell tight junctions. Biology of Reproduction $\mathbf{8 7}$ 122. (https://doi.org/10.1095/biolreprod.112.101709)

Quan W, Zheng Q, Tian J, Chen J, Liu Z, Chen X, Wu T, Ji Z, Tang J, Chu H et al. 2020 No SARS-CoV-2 in expressed prostatic secretion of patients with coronavirus disease 2019: a descriptive multicentre study in China. medRxiv 2020.03.26.20044198. (https://doi.org/10.1101/2020.03.26.2 0044198)

Rahmandad H, Lim T \& Sterman J 2020 Estimating COVID-19 underreporting across 86 nations: implications for projections and control. SSRN. (https://doi.org/10.2139/ssrn.3635047)

Rastrelli G, Di Stasi V, Inglese F, Beccaria M, Garuti M, Di Costanzo D, Spreafico F, Greco GF, Cervi G, Pecoriello A et al. 2020 Low testosterone levels predict clinical adverse outcomes in SARS-CoV-2 pneumonia patients. Andrology. (https://doi.org/10.1111/andr.12821)

Rival C, Theas MS, Guazzone VA \& Lustig L 2006 Interleukin-6 and IL-6 receptor cell expression in testis of rats with autoimmune orchitis. Journal of Reproductive Immunology 70 43-58. (https://doi.org/10.1016/j. jri.2005.10.006)

Robinson L, Gallos ID, Conner SJ, Rajkhowa M, Miller D, Lewis S, Kirkman-Brown J \& Coomarasamy A 2012 The effect of sperm DNA fragmentation on miscarriage rates: a systematic review and metaanalysis. Human Reproduction 27 2908-2917. (https://doi.org/10.1093/ humrep/des261)

Salciccia S, Del Giudice F, Gentile V, Mastroianni CM, Pasculli P, Di Lascio G, Ciardi MR, Sperduti I, Maggi M, De Berardinis E et al. 2020 Interplay between male testosterone levels and the risk for subsequent invasive respiratory assistance among COVID-19 patients at hospital admission. Endocrine 70 206-210. (https://doi.org/10.1007/s12020020-02515-x)

Schroeder M, Tuku B, Jarczak D, Nierhaus A, Bai T, Jacobsen H, Zickler M, Mueller Z, Stanelle-Bertram S, Meinhardt A et al. 2020 The majority of male patients with COVID-19 present low testosterone levels on admission to intensive care in Hamburg, Germany: a retrospective cohort study. medRxiv 2020.05.07.20073817. 
Sergerie M, Mieusset R, Croute F, Daudin M \& Bujan L 2007 High risk of temporary alteration of semen parameters after recent acute febrile illness. Fertility and Sterility 88 970.e1-970.e7. (https://doi.org/10.1016/j. fertnstert.2006.12.045)

Shan C, Yao YF, Yang XL, Zhou YW, Gao G, Peng Y, Yang L, Hu X, Xiong J, Jiang RD et al. 2020 Infection with novel coronavirus (SARS-CoV-2) causes pneumonia in Rhesus macaques. Cell Research 30 670-677. (https://doi.org/10.1038/s41422-020-0364-z)

Shen Q, Xiao X, Aierken A, Yue W, Wu X, Liao M \& Hua J 2020 The ACE2 expression in Sertoli cells and germ cells may cause male reproductive disorder after SARS-CoV-2 infection. Journal of Cellular and Molecular Medicine In press. (https://doi.org/10.1111/jcmm.15541)

Simon L, Castillo J, Oliva R \& Lewis SE 2011 Relationships between human sperm protamines, DNA damage and assisted reproduction outcomes. Reproductive Biomedicine Online 23 724-734. (https://doi. org/10.1016/j.rbmo.2011.08.010)

Song C, Wang Y, Li W, Hu B, Chen G, Xia P, Wang W, Li C, Diao F, Hu Z et al. 2020 Absence of 2019 novel coronavirus in semen and testes of COVID-19 patientsdagger. Biology of Reproduction 103 4-6. (https:// doi.org/10.1093/biolre/ioaa050)

Stanley KE, Thomas E, Leaver M \& Wells D 2020 Coronavirus disease-19 and fertility: viral host entry protein expression in male and female reproductive tissues. Fertility and Sterility 114 33-43. (https://doi. org/10.1016/j.fertnstert.2020.05.001)

Strange DP, Zarandi NP, Trivedi G, Atala A, Bishop CE, Sadri-Ardekani H \& Verma S 2018 Human testicular organoid system as a novel tool to study Zika virus pathogenesis. Emerging Microbes and Infections 7 82. (https:// doi.org/10.1038/s41426-018-0080-7)

Suede SH, Malik A \& Sapra A 2020 Histology, spermatogenesis. In StatPearls. Treasure Island (FL): StatPearls Publishing.

Takahashi T, Ellingson MK, Wong P, Israelow B, Lucas C, Klein J, Silva J, Mao T, Oh JE, Tokuyama M et al. 2020 Sex differences in immune responses that underlie COVID-19 disease outcomes. Nature. (https:// doi.org/10.1038/s41586-020-2700-3)

Ur A \& Verma K 2020 Cytokine storm in COVID19: a neural hypothesis. ACS Chemical Neuroscience 11 1868-1870. (https://doi.org/10.1021/ acschemneuro.0c00346)

Uraki R, Hwang J, Jurado KA, Householder S, Yockey LJ, Hastings AK, Homer RJ, Iwasaki A \& Fikrig E 2017 Zika virus causes testicular atrophy. Science Advances $\mathbf{3}$ e1602899. (https://doi.org/10.1126/ sciadv.1602899)

Vankadari N \& Wilce JA 2020 Emerging WuHan (COVID-19) coronavirus: glycan shield and structure prediction of spike glycoprotein and its interaction with human CD26. Emerging Microbes and Infections 9 601-604. (https://doi.org/10.1080/22221751.2020.1739565)

Wang Z \& Xu X 2020 scRNA-seq profiling of human testes reveals the presence of the ACE2 receptor, a target for SARS-CoV-2 infection in spermatogonia, Leydig and Sertoli cells. Cells 9 920. (https://doi. org/10.3390/cells9040920)

Wang W, Ye Y-X, Yao H, Wang A-S, Lin M-G, Li H-M, Sun L-Q, Wang Z-Y, Guo X-Q \& Chen H 2005 Dynamic comparative study on the changes in levels of hormones relevant to sexual function in patients with SARS and pulmonary tuberculosis. Journal of Clinical Research 22 11-13 (in Chinese).

Wang K, Chen W, Zhou Y-S, Lian J-Q, Zhang Z, DU, Gong P, Zhang L, Cui Y, Geng H-Y et al. 2020 SARS-CoV-2 invades host cells via a novel route: CD147-spike protein. bioRxiv. (https://doi.org/10.2139/ssrn.3635047)

Wei L, Sun S, Zhang J, Zhu H, Xu Y, Ma, Mcnutt Q, Korteweg MA, C \& Gu J 2010 Endocrine cells of the adenohypophysis in severe acute respiratory syndrome (SARS). Biochemistry and Cell Biology $\mathbf{8 8}$ 723-730.

Welter H, Huber A, Lauf S, Einwang D, Mayer C, Schwarzer JU, Kohn FM \& Mayerhofer A 2014 Angiotensin II regulates testicular peritubular cell function via AT1 receptor: a specific situation in male infertility. Molecular and Cellular Endocrinology 393 171-178. (https://doi. org/10.1016/j.mce.2014.06.011)

Williamson EJ, Walker AJ, Bhaskaran K, Bacon S, Bates C, Morton CE, Curtis HJ, Mehrkar A, Evans D, Inglesby P et al. 2020 Factors associated with COVID-19-related death using OpenSAFELY. Nature 584 430-436. (https://doi.org/10.1038/s41586-020-2521-4)
Wrapp D, Wang N, Corbett KS, Goldsmith JA, Hsieh CL, Abiona O, Graham BS \& Mclellan JS 2020 Cryo-EM structure of the 2019-nCoV spike in the prefusion conformation. Science 367 1260-1263. (https:// doi.org/10.1126/science.abb2507)

Wu H, Jiang X, Gao Y, Liu W, Wang F, Gong M, Chen R, Yu X, Zhang W, Gao B et al. 2019 Mumps virus infection disrupts blood-testis barrier through the induction of TNF-alpha in Sertoli cells. FASEB Journal 33 12528-12540. (https://doi.org/10.1096/fj.201901089R)

Xiao F, Tang M, Zheng X, Liu Y, Li X \& Shan H 2020 Evidence for gastrointestinal infection of SARS-CoV-2. Gastroenterology 1581831. e3-1833.e3. (https://doi.org/10.1053/j.gastro.2020.02.055)

Xu J, Qi L, Chi X, Yang J, Wei X, Gong E, Peh S \& Gu J 2006 Orchitis: a complication of severe acute respiratory syndrome (SARS). Biology of Reproduction 74 410-416. (https://doi.org/10.1095/ biolreprod.105.044776)

Yang L, Han Y, Nilsson-Payant BE, Gupta V, Wang P, Duan X, Tang X, Zhu J, Zhao Z, Jaffre F et al. 2020a A human pluripotent stem cellbased platform to study SARS-CoV-2 tropism and model virus infection in human cells and organoids. Cell Stem Cell 27 125.e7-136.e7. (https:// doi.org/10.1016/j.stem.2020.06.015)

Yang M, Chen S, Huang B, Zhong JM, Su H, Chen YJ, Cao Q, Ma L, He J, Li XF et al. 2020b Pathological findings in the testes of COVID-19 patients: clinical implications. European Urology Focus 6 1124-1129.

Zhang QL, Ding YQ, Hou JL, He L, Huang ZX, Wang HJ, Cai JJ, Zhang JH, Zhang WL, Geng J et al. 2003 Detection of severe acute respiratory syndrome (SARS)-associated coronavirus RNA in autopsy tissues with in situ hybridization. Di Yi Jun Yi Da Xue Xue Bao 23 1125-1127.

Zhang H, Yin Y, Wang G, Liu Z, Liu L \& Sun F 2014 Interleukin-6 disrupts blood-testis barrier through inhibiting protein degradation or activating phosphorylated ERK in Sertoli cells. Scientific Reports 4 4260. (https:// doi.org/10.1038/srep04260)

Zhang Y, Shi J, Rassoulzadegan M, Tuorto F \& Chen Q 2019 Sperm RNA code programmes the metabolic health of offspring. Nature Reviews: Endocrinology 15 489-498. (https://doi.org/10.1038/s41574-019-0226-2)

Zhang S, Wang X, Zhang H, Xu A, Fei G, Jiang X, Tu J, Qu G, Xu X \& Li Y $2020 a$ The absence of coronavirus in expressed prostatic secretion in COVID-19 patients in Wuhan city. Reproductive Toxicology 96 90-94. (https://doi.org/10.1016/j.reprotox.2020.06.006)

Zhang Y, Zheng L, Liu L, Zhao M, Xiao J \& Zhao Q 2020 b Liver impairment in COVID-19 patients: a retrospective analysis of 115 cases from a single centre in Wuhan city, China. Liver International 40 2095-2103. (https:// doi.org/10.1111/liv.14455)

Zhao J-M, Zhou G-D, Sun Y-L, Wang S-S, Mao P-Y, Yang J-F, Pan D, Meng EH, Li W-S, Zhou X-Z et al. 2003 a SARS coronavirus could cause multiorgan infection. Medical Journal of Chinese People's Liberation Army $\mathbf{2 8}$ 697-698, 762-763 (in Chinese).

Zhao J-M, Zhou G-D, Sun Y-L, Wang S-S, Yang J-F, Meng E-H, Pan D, Lu JY, Li L, Li J et al. 2003b Studies of pathological changes of extra-lung organs in a case of severe acute respiratory syndrome. Medical Journal of Chinese People's Liberation Army 28 480-481, 569 (in Chinese).

Zhao JM, Zhou GD, Sun YL, Wang SS, Yang JF, Meng EH, Pan D, Li WS, Zhou XS, Wang YD et al. 2003c Clinical pathology and pathogenesis of severe acute respiratory syndrome. Zhonghua Shi Yan He Lin Chuang Bing du Xue Za Zhi 17 217-221.

Zhao B, Ni C, Gao R, Wang Y, Yang L, Wei J, Lv T, Liang J, Zhang Q, Xu W et al. 2020 Recapitulation of SARS-CoV-2 infection and cholangiocyte damage with human liver ductal organoids. Protein and Cell 11 771-775. (https://doi.org/10.1007/s13238-020-00718-6)

Zheng YY, Ma YT, Zhang JY \& Xie X 2020 COVID-19 and the cardiovascular system. Nature Reviews: Cardiology 17 259-260. (https:// doi.org/10.1038/s41569-020-0360-5)

Received 17 September 2020

First decision 12 October 2020

Revised Manuscript received 5 November 2020

Accepted 16 November 2020 